\title{
Conjuntura na Saúde: Contribuições para e da Psicologia a Partir do Marxismo
}

\author{
Conjuncture in Health: Contributions to and for Psychology from Marxism
}

Coyuntura en Salud: Contribuciones hacia y desde la Psicología a Partir del Marxismo

\author{
Pedro Henrique Antunes da Costa ${ }^{1}$ \\ Universidade de Brasilia (UnB) \\ Kíssila Teixeira Mendes \\ Universidade Federal de Juiz de Fora (UFJF)
}

\begin{abstract}
Resumo
O presente artigo teórico-reflexivo objetiva apresentar as contribuições do diálogo entre Psicologia e outros campos do conhecimento para a compreensão e atuação na saúde, considerando a conjuntura de ofensiva neoliberal. A partir de conceitos e categorias da tradição marxista, o artigo tem a seguinte estrutura: breve análise conjuntural enfatizando o SUS e políticas de saúde; aportes de campos do saber-fazer para a Psicologia no trato com a saúde, especialmente a economia política; contribuições da Psicologia, exemplificadas pelas Psicologias da Libertação e Social Comunitária; e apontamentos finais, resgatando a radicalidade que gestou tais movimentos psi e na saúde. Pressupondo a incompatibilidade entre saúde e capitalismo, é imprescindível a apropriação desses saberes, pensando em como, a partir da Psicologia e das políticas de saúde, mas, sobretudo, para além delas, sanar necessidades concretas, demonstrar as contradições deste sistema, contribuindo para sua supressão e a produção de saúde.

Palavras-chave: Psicologia, Sistema Único de Saúde, saúde pública, política pública
\end{abstract}

\begin{abstract}
This theoretical-reflexive article aims to present the contributions of the dialogue between Psychology and other fields of knowledge for understanding and acting in health, considering the conjuncture of neoliberal offensive. From concepts and categories of the Marxist tradition, the article has the following structure: brief conjunctural analysis emphasizing the SUS and health policies; contributions of know-how fields to Psychology in dealing with health, especially political economy; Psychology's contributions, exemplified by the Liberation and Community Social Psychologies; and final notes, rescuing the radicality that managed such movements in Psychology and also in health. Assuming the incompatibility between health and capitalism, it is essential to appropriate this knowledge, thinking about how, from Psychology and health policies, but especially beyond them, to solve concrete needs, to demonstrate the contradictions of this system, contributing to their suppression and health production.
\end{abstract}

Keywords: Psychology, Brazilian National Health Service, public health, public policy

\section{Resumen}

Este artículo teórico-reflexivo objetiva presentar las contribuciones del diálogo entre la psicología y campos del conocimiento para comprender y actuar en salud, considerando la coyuntura de ofensiva neoliberal. Desde conceptos y categorías del marxismo, el artículo tiene la siguiente estructura: breve análisis coyuntural que enfatiza el SUS y las políticas de salud; contribuciones de los campos de conocimiento a la psicología para tratar la salud, especialmente la economía política; contribuciones de la psicología, ejemplificadas por las Psicologías de la Liberación y Social Comunitaria; y notas finales, rescatando la radicalidad que logró tales movimientos psi y en la salud. Asumiendo la incompatibilidad entre salud y capitalismo, es esencial apropiarse de este conocimiento, pensando en cómo, a partir de la psicología y las políticas de salud, pero sobre todo allá de ellas, resolver necesidades, demostrar contradicciones de este sistema, contribuyendo a su supresión y producción de salud.

Palabras clave: inPsicología, Sistema Único de Salud, salud pública, política pública 


\section{Introdução}

O presente artigo, de caráter teórico-reflexivo, objetiva apresentar algumas contribuições do diálogo entre a Psicologia e outros campos do conhecimento nas Ciências Humanas para a compreensão e atuação na saúde. Valemo-nos de pressupostos, conceitos e categorias da tradição marxista, sobretudo, da relação entre Psicologia e Saúde Coletiva (SC). A SC surge como movimento social e político atrelado ao Movimento Sanitário (MS), contribuindo para a criação e implantação do Sistema Único de Saúde (SUS) no país, tornando-se um campo científico interdisciplinar indissociável a um âmbito de práticas acerca das diversas expressões do processo saúde-doença, inclusive fora do setor saúde (Paim \& Almeida Filho, 1998). Nesse sentido, a Psicologia e outras disciplinas, como a Economia, Sociologia, Ciência Política etc., não só contribuíram para o desenvolvimento da SC como a constituem.

De acordo com Campos (2000), as contribuições do marxismo à SC se dão na transposição das limitações do positivismo e do estruturalismo, pensando ser humano e processo saúde-doença a partir de suas determinações sócio-históricas e concretas, o que não desconsidera as relações dialéticas e múltiplas mediações entre o abstrato e o concreto, o subjetivo e o objetivo, o individual e o coletivo, entre outras. Essa é uma perspectiva que também evoca a práxis como critério de verdade, concebendo a própria ciência e o processo de produção de conhecimento como práticas sociais e políticas orientadas para a construção de uma sociabilidade que não se paute na exploração do homem pelo homem, ao conceber como incompatíveis a saúde e o modo de produção capitalista, seu regime de acumulação e desigualdade estrutural.

Ao se tratar de um campo plural, não consensual, serão concebidas como principais premissas da Psicologia em interface com a SC, a partir da tradição marxista: (a) o rompimento com a concepção de homem cartesiana e organicista, compreendendo-o como sujeito histórico e social, para além de um mero corpo e/ou psiquismo, produto e produtor de sua história - só que nas condições ofertadas pelo próprio movimento histórico; (b) a superação do paradigma de saúde pública tradicionalmente pautado no modelo biomédico individualizante, com enfoque nas ações curativas e de controle; (c) a concepção e abordagem do processo saúde-doença vinculadas às lógicas e configurações societárias e suas contradições sociais, ou seja, compreendendo as determinações sociais da saúde, o que abre espaço para as contribuições advindas do diálogo entre diferentes áreas do conhecimento (Paim \& Almeida Filho, 1998; Campos, 2000).

De modo a alcançar o objetivo proposto, o artigo encontra-se estruturado da seguinte forma: 1) uma breve análise de conjuntura com ênfase para o SUS e políticas de saúde; 2) algumas contribuições de outros campos do saber-fazer para a Psicologia no trato com a saúde; 3) subsídios da Psicologia; 4) alguns apontamentos finais, resgatando a radicalidade que gestou importantes movimentos no âmbito da saúde e da própria Psicologia.

\section{Conjuntura e Saúde}

Pensar a conjuntura requer a consideração de diversas mediações e instâncias de análise que não poderão ser abarcadas. Em nossa análise, entendemos que vivemos um quadro de ofensiva do capital, com intensificação da exploração e expropriação da classe trabalhadora e sua força de trabalho, como formas de resolução de uma crise que, de acordo com 
Meszáros (2011), é estrutural. Segundo o autor, não se trata de uma mera crise cíclica, como se viu anteriormente no transcorrer do desenvolvimento capitalista, decorrente da própria lei tendencial da queda da taxa de lucro, mas de uma crise permanente e que se intensifica gradualmente. Não obstante, tem caráter universal, pois engloba o modo de produção como um todo, e não apenas alguns setores produtivos ou frações do capital isolados, e se estende globalmente.

Tal crise torna-se evidente no início dos anos 1970, com bruscas quedas nas taxas de lucro e padrão de sobreacumulação, juntamente de aumento nos índices inflacionários nos países ditos desenvolvidos, e, depois, atingindo a periferia do sistema capitalista. De modo geral, denota o fim da ascendência histórica do capital no século XX, isto é, um freio em seu impulso e capacidade expansionista (Meszáros, 2011). Apesar de "respiros" econômicos nos países de capitalismo avançado nas décadas de 1980 e 1990, resultantes da financeirização do capital, o prosseguir dos anos demonstra tal caráter estrutural, com agudização em 2008 e reflexos posteriores. Tudo isso explicita o caráter antagônico do metabolismo social capitalista e seus limites intrínsecos, cujas saídas, por dentro do próprio sistema, não deram as respostas desejadas, como: a reestruturação produtiva, a acumulação flexível e o neoliberalismo. Não sanaram tais limitações - estruturais e que requerem saídas "para além do capital" (Meszáros, 2011) - e potencializaram a concentração da riqueza socialmente produzida e a condição de subordinação e dependência dos países subdesenvolvidos, como o Brasil, potencializando o caráter destrutivo desse sistema em seu atual estágio de desenvolvimento. Atualmente, tal faceta bárbara pode ser vista em várias esferas: com o 1\% mais rico detendo $87 \%$ da riqueza socialmente produzida (OXFAM, 2018); o processo de destruição exponencial da natureza; crises humanitárias, produzindo inúmeros refugiados; a ascensão de atores, discursos e práticas fascistas; guerras, entre outras.

Mesmos em países com altas taxas de crescimento nos últimos anos, sobretudo os asiáticos, como a China e a Índia, observamos um cenário de estagnação ou queda. Segundo o Fundo Monetário Internacional (International Monetary Fund [FMI], 2019), a economia global, que apresentava lenta recuperação posterior à "crise de 2008", tornou a retrair na segunda metade de 2018, com as estimativas caindo de 3,9\%, em 2018 e 2019, para 3,6\% e $3,3 \%$, respectivamente. No Brasil, entre 2014 e 2016, os índices econômicos foram negativos $(-0,38 \%,-4,59 \%$ e-2,76\%, respectivamente), sendo que, em 2017 e 2018, o crescimento foi de apenas 0,21\% e 0,69\%.

E como tal histórico e conjuntura repercutem no âmbito da saúde brasileira? Primeiramente, falar de saúde no país significa adentrar num campo que, apesar dos tensionamentos e disputas, apresentou uma hegemonia liberal, de característica excludente, com desigualdade de acesso, subfinanciamento, "separação entre ações curativas e preventivas e de promoção de saúde, e concentração de recursos na assistência médico-hospitalar" (Yamamoto \& Oliveira, 2010, p. 13). No entanto, num contexto de efervescência social nos anos 1970 e 1980, que se desvela nas lutas pela democratização da saúde, o MS surge, ganha fôlego e, junto de demais movimentos, organizações e representações da classe trabalhadora, insere-se na disputa pela hegemonia, contribuindo para a promulgação do SUS, com a Constituição Federal de 1988 e as leis 8.080/1990 e 8.142/1990. A saúde, de caráter universal, passa a se vincular à seguridade social (juntamente às previdência e assistência sociais), entendida como dever do Estado e direito de todos. 
Contrariamente ao que acontecia em boa parte do mundo, sobretudo nos países considerados desenvolvidos, todo esse esforço configurou uma parca, mas importante tentativa de implementação de um Estado de Bem-Estar Social (EBES). Contudo, uma série de contradições atravessam a própria formulação e promulgação da CF, expressas na saúde, entre outros exemplos, pela complementaridade da participação do setor privado, num paradoxo entre saúde-direito ou mercadoria (para maiores detalhes sobre este processo e a participação da Psicologia, ver Yamamoto \& Oliveira, 2010).

Num panorama de crise dos EBES, atrelada à crise estrutural, tal ímpeto e suas conquistas nunca foram consolidados em totalidade no país, com elementos relevantes não sendo implantados ou desvirtuados (Yamamoto \& Oliveira, 2010), no que Behring denomina (2018, p. 61) de "contrarreforma do Estado e ajuste fiscal permanente". Isso já ocorre no governo de Fernando Collor de Mello (1990-1992), com a adesão ao neoliberalismo, mas é nos mandatos de Fernando Henrique Cardoso (1995-2002) que tal doutrina se espraia e enraíza, consolidando os preceitos do FMI e Consenso de Washington. Acarreta, assim, a desregulamentação do mercado e desmonte do colchão de direitos sociais, precarização (com focalização e descentralização das políticas), financeirização e privatizações, sejam elas explícitas, sejam elas escamoteadas por concessões, parcerias público-privadas, filantropização etc. (Yamamoto \& Oliveira, 2010).

Inúmeras diferenças marcam tal período dos governos de Luiz Inácio Lula da Silva (20032010) e Dilma Rousseff (2011-2015). A despeito do subfinanciamento do SUS ser "uma política de Estado" (Soares \& Santos, 2014, p. 25), podemos elencar as seguintes mudanças: incentivo à produção de insumos; maior relevo a pautas como saúde mental, saúde da família e urgência; agenda social de combate à pobreza articulada à atenção básica; incentivo ao controle social; novas instância regionais via Pacto pela Saúde, de 2006; Programa Mais Médicos, após a saúde ser pauta prioritária nas manifestações de 2013 etc. (Magno \& Paim, 2015; Castro et al., 2019).

Entretanto, há uma continuidade na condução política macroeconômica neoliberal. Com o "objetivo central de assegurar o cumprimento de metas de inflação e a obtenção de elevados superávits primários", o resultado foi uma "constante pressão para que o gasto público fosse diminuído, o que, no SUS, assumiu a forma de contingenciamento" (Mendes, Ianni, Marques, Ferreira, \& Silva, 2017, p. 854). Por exemplo, Soares e Santos (2014), ao compararem os governos FHC, Lula e os dois primeiros anos de Dilma Rousseff, constataram que, apesar do crescimento orçamentário, o comportamento geral de gastos na saúde não diferiu. De 1995 a 2012, o gasto federal com a saúde variou de 1,6\% a 1,8\% do Produto Interno Bruto (PIB), e a participação da União nestes gastos caiu de 74,38\%, em 1990, para 45,80\%, em 2012, responsabilizando mais estados e municípios. Segundo Behring (2018), em 2012, houve contingenciamento de $\mathrm{R} \$ 55$ bilhões do orçamento, com $\mathrm{R} \$ 5,47$ bilhões apenas na saúde. Algumas medidas dos governos petistas são bastante ilustrativas da lógica neoliberal, como: a criação, em 2011, da Empresa Brasileira de Serviços Hospitalares (EBSERH) para gerenciar Hospitais Universitários; o fomento às Organizações Sociais de Saúde (OSSs) e parcerias público-privadas; a sanção da Lei n. 13.097, de 19 de janeiro de 2015, permitindo a entrada do capital estrangeiro na saúde; isenções fiscais, beneficiando planos de saúde e conglomerados de oferta de serviços etc. (Mendes et al., 2017; Behring, 2018; Viana \& Silva, 2018). 
No entanto, a partir do golpe de 2016, materializa-se um salto qualitativo na gestão neoliberal do país, o que nos faz concordar com Behring (2018), ao apontar um novo momento de "ofensiva desenfreada" (p. 62) do capital, visando adequar-se à conjuntura internacional pós-2008. Esse momento tem suas raízes no histórico sucintamente descrito, mas germinando com os sopros tardios da crise de 2008 no Brasil e anabolizando-se a partir de 2013, quando se escancaram as limitações da gestão conciliatória petista que não mais satisfaz a classe dominante e é enfraquecida em substratos da classe trabalhadora. No período que compreende o governo Temer (2016-2018) e início da gestão de Jair Bolsonaro (2019), constatamos essa ofensiva do capital, coadunada com uma ascensão conservadora: um "populismo de extrema-direita" (Castro et al., 2019), acarretando processos de desmonte e retrocessos nas políticas sociais e, consequentemente, do SUS, numa intensidade, volume e velocidade ainda não vistos.

Gostaríamos de destacar as seguintes medidas desse período (2016-2019), com impactos diretos nas políticas sociais e, mais especificamente, na saúde: (a) Emenda Constitucional 95/2016, que limita o "gasto" público por 20 anos, poupando juros e encargos da dívida pública; (b) contrarreformas trabalhista e da previdência; (c) aumento das renúncias fiscais (dedução dos gastos com planos de saúde no Imposto de Renda e concessões) para planos e empresas fornecedoras de serviços de saúde, concomitante à proposta de planos de saúde populares; (d) crescentes transferências dos recursos públicos às OSS; (e) nova Política Nacional de Atenção Básica, de 2017, com relativização da universalidade, segmentação do acesso, recomposição das equipes e reorganização do processo de trabalho; (f) fim da cooperação com o governo de Cuba no programa "Mais Médicos", aumentando lacunas na atenção básica, especialmente em municípios e territórios pequenos e do interior; (g) fechamento de centenas de farmácias populares; (h) suspensão de contratos para fabricação e distribuição de medicamentos gratuitos no SUS; (i) atrasos nas áreas voltadas para a população LGBTI+, de direitos reprodutivos e educação sexual para adolescentes, fomentadas pelo conservadorismo e fundamentalismo religioso; (j) retrocessos na saúde mental e com álcool e outras drogas, com centralidade nas Comunidades Terapêuticas, reinstitucionalização dos Hospitais Psiquiátricos e internação involuntária, mercantilizando e privatizando os cuidados, aliada ao retorno da lógica manicomial (Cunha, 2017; Mendes et al., 2017; Castro et al., 2019).

De acordo com Castro et al. (2019), todas estas mudanças, circunscritas à condução política e econômica do país, podem reverter as realizações do SUS, que propiciaram inúmeras melhorias nas condições de vida e maior equidade em saúde, colocando em xeque a sua continuidade. Temos, portanto, novos, mas também velhos desafios (redinamizados e reconfigurados), ocasionando pioras substanciais na saúde da classe trabalhadora (Viana \& Silva, 2018). Assim, fomenta-se a supressão da saúde-direito pela saúde-mercadoria (sustentada na concepção de "cidadania-consumista"), o caráter focalizado das políticas em detrimento da universalidade e a intensificação da gestão via subfinanciamento e sucateamento, com privatização dos serviços e hegemonia do modelo biomédico, especializado, hospitalocêntrico e individual. A partir disso, pensaremos os aportes para e da Psicologia (Viana \& Silva, 2018; Castro et al., 2019). 


\section{Contribuições para a Psicologia no trato com a saúde}

Inicialmente, é importante salientar que o processo de particularização dos campos do saber e, neles, a própria lógica de (super)especialização configuram-se como abstrações, visto que a realidade não se dá de maneira fraturada, como essas ramificações dão a entender. Expressam, portanto, o próprio movimento do modo de produção capitalista, numa divisão social do trabalho científico, o qual a Psicologia não está imune; pelo contrário, isso está em suas fundações (Lacerda Júnior, 2010). O exercício que aqui fazemos, ao contrário de significar a perpetuação dessa lógica de fragmentação do conhecimento e fratura da totalidade, serve a fins didáticos, de modo a explicitar o caráter confluente das já consolidadas disciplinas das Ciências Humanas.

Conforme Lacerda Júnior (2010), a própria Psicologia surge como disciplina autônoma em meados do século XIX, ao refletir o processo de decadência ideológica da burguesia, que foi de revolucionária à classe dominante com a consolidação do capitalismo. A compreensão da autoatividade humana pela Psicologia, focalizando potencialidades para a sua própria libertação e desenvolvimento pleno, deu lugar à compreensão deste ser pelo controle, ajustamento, justificando e naturalizando a ordem social (Lacerda Júnior, 2010). Daí advém a hegemonia individualista, psicologizante e, consequentemente, vinculada à ordem da Psicologia, enquanto expressão dela e sua conformadora, sintetizada por Lacerda Júnior (2010), na máxima: “[É] possível explicar os problemas enfrentados pela humanidade, olhando para o que se passa na cabeça dos indivíduos e não tanto para um mundo marcado por enormes desigualdades de classe" (p. 370).

Por isso, o referencial marxista apresenta-se como relevante para se pensar a realidade em que vivemos e os conhecimentos que nela são produzidos, na tentativa de sua compreensão e, mais especificamente, da Psicologia, num sentido crítico. Entretanto, concordando com Yamamoto (1987), em virtude da gênese da Psicologia e sua constituição, é paradoxal uma "Psicologia marxista", de modo que isso seria negar o próprio marxismo, o que não significa que ela não possa se inspirar e incorporar contribuições dele. O autor aprofunda suas reflexões iniciais propondo, inclusive, o movimento de negação da Psicologia, em vez de buscar reformulá-la, entendendo que a subjetividade não é objeto de estudo de uma ciência particular, pois remete à vida social como um todo (Yamamoto, 1987; Lacerda Júnior, 2010).

Pretendemos, a partir do movimento do real e da totalidade, compreender as particularidades brasileiras, evitando, por um lado, idealizações e romantizações acerca do papel e da (in)capacidade da Psicologia, como complexo particular de compreensão da realidade em que vivemos, e, por outro lado, não incorrer também em imobilismos e fatalismos. O esforço é o de entender como a Psicologia pode contribuir para a saúde, tomando como horizonte a supressão dessa sociabilidade adoecedora e desumanizante e, por conseguinte, de si mesma (e das políticas sociais). Só que, para isso, buscaremos, primeiramente, apresentar algumas contribuições para o campo psi no trato teórico e prático com as políticas de saúde, a partir da síntese dos seguintes pontos: (a) a importância da dimensão econômica e as contribuições da (crítica à) economia política; (b) o caráter do Estado e das políticas sociais no capitalismo brasileiro; e (c) a saúde e seus atrelamentos com a "questão social" (QS).

Remetendo-nos ao breve histórico e à análise conjuntural do artigo, observamos a refuncionalização do Estado nos moldes neoliberais como forma de sanar a crise estrutural, 
com intensificação do saqueamento do fundo público. No atual estágio de desenvolvimento capitalista, tais engendramentos servem para atender às necessidades do capital, sobretudo o financeiro, fomentando mais desigualdade e destruição (Meszáros, 2011). Assim, estão coadunadas com uma série de ações, como as Desvinculações de Receitas da União (DRU), que retiram $20 \%$ dos recursos da seguridade social para pagamento de juros da dívida, e a Lei de Responsabilidade Fiscal (n. 101/2001), condicionando os gastos à capacidade de arrecadação de tributos. Em suma, servem à manutenção do tripé macroeconômico implementado no segundo mandato de FHC e mantido desde então: meta de inflação (com o país tendo uma das maiores taxa de juros reais do mundo), câmbio flutuante e meta fiscal de produção de superavit primário para o pagamento, novamente, de juros da dívida pública. Nesse sentido, para que a Psicologia possa, primeiramente, compreender a conjuntura brasileira diante da totalidade, contribuindo para vislumbramos e trilharmos caminhos de superação, é necessário que olhe para as relações produtivas, isto é, volte-se para a dimensão econômica e se aproprie das contribuições da (crítica à) economia política (Mendes et al., 2017). Parafraseando a assertiva atribuída a James Carville, então assessor da campanha presidencial de Bill Clinton em 1992: é a economia-política, estúpido!

Com isso, não pretendemos incorrer num economicismo mecanicista, de explicações monocausais, muitas das vezes impetrado a Marx (seja por críticos, seja por, até mesmo, alguns "marxistas"). Apesar da primazia da "estrutura econômica da sociedade", que corresponde à totalidade das relações produtivas e que forma uma superestrutura (política, jurídica etc.), ambas se determinam reflexivamente (Marx, 1859/2008). Como ironiza Netto (2011), a produção de conhecimento não se dá pela "simples 'aplicação' do método de Marx, que haveria de 'solucionar' todos os problemas: uma análise 'econômica' da sociedade forneceria a 'explicação' do sistema político, das formas culturais etc." (p. 13).

Isso nos leva ao debate sobre o caráter do Estado e das políticas sociais no capitalismo, considerado seu atual estágio de desenvolvimento e as particularidades brasileiras. Embora a conjuntura faça com que consideremos a necessidade de defender as políticas sociais, como conquistas da própria classe trabalhadora (vide o exemplo do SUS), é preciso ressaltar a natureza limitada de tais políticas, que, como braço do capital, e agindo aos seus moldes, não são capazes de (ou almejam) superar as questões estruturais anteriormente sinalizadas. O Estado com sua ação via políticas sociais não busca solucionar problemas estruturais, pois, antes de tudo, é produto destas estruturas; é sustentáculo das relações de produção, ao passo que também as conforma.

A partir disso, podemos chegar a duas conclusões: a primeira é de que não se pode compreender as políticas de saúde de maneira ensimesmada, mas vinculadas à totalidade social, ao modo de produção capitalista; e a segunda é de que a transformação social, ou seja, a mudança radical dessa sociabilidade, não se dará por meio do Estado e pelas políticas sociais. Por isso, encaramos as políticas como mediadoras, isto é, meios para construção de lutas mais amplas, e não como fim em si mesmas, sem que percamos de vista sua natureza capitalista. Daí o fortalecimento de saídas coletivas via partidos políticos, sindicatos, demais movimentos sociais e formas organizativas da classe trabalhadora, considerando suas especificidades, ainda é caminho imprescindível; não à toa, também tais iniciativas são alvo dessa ofensiva. 
Considerando o panorama de crise estrutural, a refuncionalização e o redimensionamento do Estado voltam-se para amenizar os efeitos dessa crise revertendo a tendência de queda nas taxas de lucro e valorizando o capital. Consequentemente, na gestão das políticas sociais e da saúde, já predominantemente focalizadas, é cada vez mais presente uma racionalidade mercantil e seu conjunto de técnicas gerenciais, justificadas por discursos de racionalização, eficiência, eficácia e modernização (Carnut \& Mendes, 2018). Assim, esvazia-se a natureza política do Estado, sua base econômica, restrita ao resultado de operações matemáticas (deficits e superavits), e suas mediações.

Por trás das narrativas de que o problema do Estado e das políticas é a corrupção ou o mau gerenciamento, de que bastam boas ideias e mais trabalho, está a sua vinculação e subserviência ao capital, tendo como resultantes "as parcerias público-privadas, as contratualizações por resultados e as remunerações variáveis por desempenho" que caracterizam "o estágio mais avançado da espoliação" da classe trabalhadora (Carnut \& Mendes, 2018, p. 115). Reforça-se a concepção e trato da saúde como mercadoria, dos trabalhadores como meros técnicos, e o trabalho e seus resultantes viram números-síntese que "em quase nada expressam a complexidade dos sistemas de saúde" (p. 118). Logo, se a lógica e procedimentos regentes são os do mercado, por que não conceder as políticas e serviços ao próprio? Temos, assim, um dos principais argumentos para as privatizações na saúde, coadunados por processos de subfinanciamento e sucateamento, deslocando a "solução" para a iniciativa privada.

Toda essa discussão no remete a Behring (2018), quando esta postula que, no presente momento de intensificação da exploração e expropriação da classe trabalhadora como tentativas de sanar a crise do capital, "é ainda mais impensável que a política social possa retrair a base social da exploração" (p. 49), apesar de sua importância no atendimento às necessidades objetivas e concretas dessa classe. Segundo a autora, se as políticas sociais não fizeram isso quando se universalizaram - pois nunca foi seu objetivo -, não será agora que farão, quando se encontram cada vez mais focalizadas e subservientes ao capital, sobretudo o financeiro, servindo como compensação à intensificação dessa exploração (Behring, 2018).

E falar sobre as políticas sociais significa remeter-se à QS, afinal elas abordam, justamente, suas expressões. A QS engloba o conjunto de manifestações da desigualdade inerente à sociabilidade capitalista, como a pobreza, o desemprego estrutural etc., cuja gênese está no próprio modo de produção capitalista que se pauta no antagonismo entre capital e trabalho e na exploração do segundo pelo primeiro (Netto, 2001). Assim, ao se voltar para as expressões da QS, e não o que a produz, as políticas sociais miram nos sintomas, e não nas causas, reforçando seu caráter limitado. Ademais, tais expressões passam a ser parcializadas e abordadas fragmentadamente pelas políticas sociais (da saúde, da assistência social etc. e de maneira especializada dentro destas), desconsiderando-as como manifestações de uma questão una, a QS.

Tudo isso nos remete à discussão introduzida no início do artigo, sobre a determinação social da saúde, ou seja, entendendo a saúde vinculada à QS e não como algo em si. Dessa forma, a noção de "determinantes sociais de saúde", chancelada pela Organização Mundial da Saúde (OMS), torna-se passível de críticas por se contrapor à de determinação social da saúde e atrelamento à QS. Com isso, reforçamos oposições feitas, inclusive, por autores e perspectivas não marxistas (Garbois, Sodré, \& Dalbello-Araujo, 2017). 
De modo geral, critica-se a forma como o "social" é concebido, como algo externo ao sujeito, um amontoado de fragmentos autônomos da realidade, abstraídos como "variáveis", "recortes" per si, que devem ser correlacionados para a compreensão de determinados estados de saúde. Muitas das vezes aparecem como sinônimos de "comportamentos", "estilos de vida", que remetem ao indivíduo - e o responsabilizam - contribuindo para a manutenção da ordem. Apesar de encontrarem determinadas relações entre restrições socioeconômicas e a saúde - algumas delas óbvias -, desconsideram o próprio movimento do real e sua apropriação pelo pensamento como síntese de múltiplas mediações. Na melhor das hipóteses, voltam-se para a aparência fenomênica, sem compreender a sua essência, que remete à própria configuração de nossa sociabilidade e seu caráter desigual, como denota o conceito de QS (Souza, Silva, \& Silva, 2013; Garbois et al., 2017).

Consonantes a Souza, Silva e Silva (2013), é no processo de acumulação capitalista, na contradição capital-trabalho, que se encontra a determinação material essencial para a saúde, de modo que possamos compreendê-la como expressão direta da QS ou atravessada por ela. Portanto, pensar a saúde significa remetê-la à totalidade social, mediada pelas particularidades sociais e que se produzem nas relações sociais e nas singularidades dos sujeitos. Ao ser constitutiva da sociabilidade capitalista, a supressão da QS passa pela dissolução da primeira e, por conseguinte, do próprio Estado burguês e das políticas sociais como formas de gerenciá-la - jamais suplantá-la.

\section{Contribuições da Psicologia}

Diante das reflexões, como pensar contribuições da Psicologia à saúde? Primeiramente, cabe romper com os tradicionais processos de psicopatologização e ajustamento, de transposição da prática da clínica de consultório privado e identificada com modelos psicoterapêuticos individualizantes comuns ao modelo biomédico para os dispositivos do SUS e contextos sociocomunitários, entre outros problemas históricos na área (Yamamoto \& Oliveira, 2010). Conforme argumentado, tais características se devem à própria gênese e constituição da Psicologia. Somadas às limitações de um campo particular do conhecimento e prática em compreender e abarcar a realidade, fazem com que tenhamos que ir além dela, caso queiramos nos aproximar o máximo possível de apreender o movimento do real e transformar tal realidade (Yamamoto, 1987; Lacerda Júnior, 2010).

A despeito de tais insuficiências, movimentos alternativos, ou contra-hegemônicos, conformando o que se denominou de "Psicologia Crítica", desenvolveram-se no seio da Psicologia latino-americana, demonstrando algumas possibilidades (Lacerda Júnior, 2013). Considerando a pluralidade que paira sob tal nomenclatura e as contradições existentes sobre o caráter crítico de algumas destas - se contribuem ou não para a "denúncia e desmistificação da realidade existente", possibilitando "processos emancipatórios" (Lacerda Júnior, 2013, p. 216) -, gostaríamos de citar a Psicologia da Libertação (PL) e a Psicologia Social Comunitária (PSC).

A PL é desenvolvida por Ignácio Martín-Baró (1942-1989), a partir da realidade de El Salvador nos anos 1970 e 1980, marcada pelo imperialismo estadunidense, antagonismo social e guerra civil. Fundamenta-se na Teologia e Filosofia e Libertação, pedagogia freireana, com alguns aportes marxistas, entre outros. Para o autor, a teoria e o trabalho do psicólo- 
go devem ser definidos em função das circunstâncias concretas da população; no caso, as maiorias populares, assumindo em seu horizonte a contribuição para processos de desideologização e conscientização (Martín-Baró, 2006), ao "acompanhar as maiorias pobres e oprimidas em sua luta por constituir-se como povo novo em uma terra nova" (Martín-Baró, 1996, p. 23).

A PSC no Brasil, semelhante a outros países latino-americanos, nasceu da preocupação em deselitizar a profissão, desenvolvendo práticas transformadoras que fortalecessem movimentos sociais e as lutas populares ante o contexto ditatorial e de desigualdade social. Por isso, sua gênese está imbricada nos chãos das fábricas, sindicatos, partidos, comunidades mais carentes etc. Posteriormente, institucionaliza-se, buscando maior sistematização teórica e vinculando-se às universidades e políticas sociais (Freitas, 2011), incorporando possibilidades, mas também sendo atravessada pelas limitações destes espaços e políticas (Lacerda Júnior, 2013). Atravessada também pelo pluralismo teórico, metodológico e político, fazemos menção específica à PSC de inspiração marxista, o que não significa que outras perspectivas não compartilhem de alguns pressupostos aqui mencionados.

Em ambos os casos, parte-se da realidade que conforma as maiorias populares exploradas e oprimidas e se volta para ela, num sentido de contribuir para sua transformação; uma Psicologia e práxis posicionadas, com o psicólogo enquanto ator político - e não apenas um profissional técnico - vinculado à própria classe trabalhadora (Martín-Baró, 1996; 2006). Tanto a PL quanto a PSC buscam não apenas aproximar fisicamente a psicologia da população pobre, mas transformar suas próprias bases ontológico-epistemológicas, modificando o quefazer e a identidade da Psicologia (Lacerda Júnior, 2013).

A reformulação do conceito de consciência, então, faz-se fundamental para compreender a conscientização, que deve ser tida como o saber sobre si e sobre o mundo, a partir de três pressupostos: a concepção dialética de que o ser humano se modifica ao transformar sua realidade; com a desnaturalização e decodificação do mundo, há novas possibilidades de ação; e a nova concepção de mundo conduz a uma nova visão de si. Assim, o processo de conscientização se volta à injustiça social a partir de suas raízes objetivas, visando à recuperação da memória histórica, mesmo que a Psicologia não seja capaz de superar essa realidade concreta em si (Martin-Baró, 1996; 2006). Não se trata de uma tomada de consciência individual e meramente subjetiva, mas sim coletiva, que vise às condições objetivas comunitárias, considerando as limitações vigentes, mas tendo em vista fortalecimento coletivo (Guzzo \& Lacerda Júnior, 2007). Portanto, o presente resgate, partindo de exemplos concretos, permite-nos vislumbrar formas de pensar e agir no presente, inclusive, para além da Psicologia. Isso nos leva a considerar a produção dos conceitos de ser humano, subjetividade e consciência com o capitalismo, sinalizando como a Psicologia pode considerá-los fugindo do dualismo indivíduo-sociedade, concreto-abstrato e indo além "das concepções de que o psiquismo é uma realidade privada" (Morais \& Lacerda Júnior, 2019, p. 175).

Conforme Morais \& Lacerda Júnior (2019), a própria noção de subjetividade e a naturalização do conceito de individualidade e liberdades individuais são inéditas do capitalismo, ligadas, essencialmente, à necessidade de mecanização operária e pela propriedade privada. Assim, as experiências sensíveis são atravessadas por narrativas que conduzem - se apresentando como naturais - ao individualismo, à imediatez e ao consequente afastamento dos domínios coletivos: "O funcionamento psíquico da sociedade burguesa passa fundamental- 
mente por uma normatividade que reduz as possibilidades dos indivíduos à mera produção e reprodução dos meios materiais de vida" (Morais \& Lacerda Júnior, 2019, p. 175).

Voltando à conjuntura, Barreto \& Carmo (2007) apontam para novos padrões de adoecimentos e mortalidade da população brasileira, com destaque para a desigualdade e a pobreza, elencando as seguintes demandas: doenças crônicas, infecciosas e degenerativas, violência, situação nutricional, doenças alérgicas, saúde bucal, saúde da população negra e indígena e saúde mental. Tais exemplos não reforçam a necessidade de considerarmos a saúde vinculada à QS?

Sobre a saúde mental, cuja própria denominação pode indicar uma fragmentação da saúde e sua determinação social, é importante pontuar que, segundo relatório do Ministério da Fazenda (Brasil, 2017), os transtornos mentais foram a terceira principal causa de afastamentos do trabalho no Brasil no período de 2012 a 2016. Considerando a lógica que buscamos imprimir, poderíamos pensar que o trabalho é a causa de afastamentos do trabalho. Isso fica mais claro quando o mesmo relatório aponta para a lógica produtivista e competitiva do capitalismo globalizado como causa de adoecimento mental que é, antes de tudo, social. E quem é, predominantemente, chamada a se debruçar sobre estas mazelas, senão a Psicologia?

Este novo padrão de adoecimento, estritamente vinculado à precarização das relações de trabalho e agudização da relação capital-trabalho, é reproduzido em todos os âmbitos da vida. Vasconcelos (2012), de forma esquemática, aponta que o desemprego e o trabalho precário conduzem um ciclo de desamparo e depressão, falta de perspectiva futura, mobilização no crime e narcotráfico, violência, aumento de quadros pós-traumáticos e impacto nos serviços de saúde mental. Fica evidente, dessa forma, que saúde e saúde mental não podem ser vistas e abordadas de forma apartada de si e da conjuntura, das condições econômicas e, sobretudo, da centralidade do trabalho no modo de produção capitalista. Tal norte contribui para "desindividualizar" saúde, saúde mental, os transtornos e o próprio saber-fazer psi, mesmo nos casos em que se parta do indivíduo.

O "como" fazer isso nos remete às reflexões e aos exemplos supracitados (PL e PSC). Contudo, entendemos que é a própria realidade que nos responderá, evitando a comodidade limítrofe de receituários prontos e ampliando o leque de possibilidades. Além disso, mais importante que se perguntar sobre o "como" é se indagar "em benefício de quem" ele se volta, assim como "a partir de quem", em vez do "onde", e, principalmente, quais são as consequências concretas históricas desse quefazer psi (Martín-Baró, 1996).

Dessa forma, a Psicologia, mesmo com suas limitações, pode fornecer importantes subsídios, seja na promoção de saúde, seja na prevenção, no tratamento e em outras formas não institucionalizadas de fortalecimento dos contextos sociocomunitários e maiorias populares, desde que vinculando a formação da subjetividade e dos próprios seres ao modo de produção capitalista, considerando sua razão-de-ser neoliberal. Afinal, é nessa configuração que nos encontramos e produzimo-nos. Consequentemente, é dela que se extrai a concepção e teorização sobre a dimensão subjetiva - daí, novamente, a importância da economia política e de outros campos teórico-práticos. Se isso pode ser feito também por outros campos, não só entendemos que sim, como encorajamos. Se significará uma perda de relevância da Psicologia, respondemos com Martín-Baró (2006), para quem "una Psicología de la liberación requiere una liberación previa de la Psicología" (p. 14). 
Por fim, pensamos que, dessa forma, a Psicologia pode contribuir, minimamente, para o campo da saúde brasileira: desmistificando a racionalidade neoliberal-capitalista e fomentando contrapontos a ela (e a si mesma) e na própria produção de saúde, por uma práxis crítica e transformadora, mesmo que obstaculizada pela ordem e conjuntura, reverberando, até mesmo, no seu trato com as patologias e os traumas oriundos dessa realidade. Isso pode parecer pouco - e é - diante dos desafios que temos enquanto sociedade, mas é imperioso a uma Psicologia que se comprometa com as necessidades reais das maiorias populares e a mudança social. E isso nos remete, novamente, a Martín-Baró (1980/2015), que, ao falar do psicólogo no processo revolucionário, considera que este deve:

... anticipar los problemas que irán surgiendo, para facilitar y humanizar el paso a la nueva sociedad. A las inmediatas, toca atender los "traumas" del conflicto y la desintegración social. A mediano y largo plazo, toca colaborar en la edificación social de un hombre nuevo, basado en necesidades menos individualistas y en objetivos de justa solidaridad (p. 487).

\section{Resgate da Radicalidade: Psicologia, Saúde Coletiva e Políticas de Saúde}

Ensejando explicitar mais contribuições para e da Psicologia na saúde, gostaríamos de terminar o artigo voltando atrás, ao entender a realidade como processo, e rememorando o histórico e as raízes de constituição do próprio SUS, SC e MS, de modo a resgatar suas radicalidades. Fazemos isso, pois localizamos nesse processo elementos imprescindíveis para os dias atuais. Assim como apregoa Marx (1844/2010), "[s]er radical é agarrar a coisa pela raiz. Mas a raiz, para o homem, é o próprio homem" (p. 151).

Conforme apresentado, a SC e o MS nascem, justamente, em um cenário de ebulição social pelo fim da ditadura e reabertura democrática, agregando outras reivindicações e movimentações. Construções teórico-práticas que localizaram a saúde numa totalidade, como um direito, e não benesse ou mercadoria, compreendendo que democratizar a vida era democratizar a saúde, e vice-versa; que, portanto, se colocavam lado a lado das lutas da classe trabalhadora, não sendo neutras, imparciais, meras abstrações ou restritas ao campo e trabalhadores da saúde.

Dessa forma, o resgate da radicalidade do MS e SC mostra-se compatível com as sinalizações feitas e as raízes de movimentos na Psicologia crítica latina, ilustrados pela PL e PSC. É desse resgate que as sinalizações aqui postas emergem, mostrando-nos que nem sempre a roda precisa ser reinventada. Por sua vez, toda essa radicalidade nos direciona para as raízes do próprio ser humano, que, ao se fazer, por meio de sua ação, modificando o meio e a si mesmo, produz e transforma a sociedade.

Como disse Sérgio Arouca (Radis, 2003), o objetivo do MS era "conquistar a democracia para então começar a mudar o sistema de saúde, porque tínhamos muito claro que ditadura e saúde são incompatíveis. Nosso primeiro movimento era, portanto, no sentido de derrubar a ditadura, e não de melhorar a saúde" (p. 356). Entendemos que saúde e capitalismo - valendo-se ou não de regimes formalmente ditatoriais - são incompatíveis (ao menos para a maioria), mas que melhorar a saúde e derrubar a sociabilidade que lhe obstaculiza não são processos excludentes. Assim, que o movimento ainda seja o de derrubar essa sociabilidade "ditatorial" de uns poucos sobre muitos, mesmo que com vernizes democráticos, e, nisso, melhorar e produzir mais saúde. Enquanto isso, sem ingenuidade, pensar em como é 
possível, a partir da Psicologia (em diálogo com outros campos do saber-fazer) e das políticas de saúde como mediadoras, e, sobretudo, para além delas, sanar necessidades concretas, demonstrar as contradições deste sistema e contribuir para o fortalecimento dos sujeitos revolucionários. Estes que são os responsáveis pela supressão dessa ordem, juntamente à das políticas e, quiçá, da Psicologia, ao menos como se constituiu hegemonicamente.

\section{Referências}

Barreto, M., \& Carmo, E. (2007). Padrões de adoecimento e de morte da população brasileira: os renovados desafios para o Sistema Único de Saúde. Ciência \& Saúde Coletiva, 12(Supl.), 1779-1790.

Behring, E. R. (2018). Estado no Capitalismo: Notas para uma leitura crítica do brasil recente. In I. Boschetti, E. R. Behring, \& R. L. Lima (Orgs.), Marxismo, política social e direitos (pp. 39-72). São Paulo: Cortez Editora.

Brasil. (2017). Ministério da Fazenda. 1o Boletim Quadrimestral sobre Benefícios por Incapacidade de 2017 Adoecimento Mental e Trabalho: A concessão de benefícios por incapacidade relacionados a transtornos mentais e comportamentais entre 2012 e 2016. Brasília-DF: Ministério da Fazenda.

Campos, G. W. S. (2000). Saúde pública e saúde coletiva: Campo e núcleo de saberes e práticas. Ciência \& Saúde Coletiva, 5(2), 219-230.

Carnut, L., \& Mendes, A. (2018). Capital-Estado na crise contemporânea: O gerencialismo na saúde pública. Argumentum, 10(2), 108-121.

Castro, M. C., Massuda, A., Almeida, G., Menezes-Filho, N. A., Andrade, M. V., Noronha, K. V. M. S. . . A Atun, R. (2019). Brazil's unified health system: The first 30 years and prospects for the future. Lancet, 394(10195), 345-356.

Cunha, J. (2017). O direito à saúde no Brasil: da redemocratização constitucional ao neoliberalismo de exceção dos tempos atuais. Cadernos Ibero-Americanos Direito Sanitário, 6(3), 65-89.

Freitas, M. F. Q. (2011). Psicologia na comunidade, psicologia da comunidade e psicologia (social) comunitária: Práticas da psicologia em comunidade nas décadas de 60 a 90. In R. H. F. Campos (Org.), Psicologia social comunitária: Da solidariedade à autonomia (pp. 54-80). Petrópolis: Vozes.

Garbois, J. A., Sodré, F., \& Dalbello-Araujo, M. (2017). Da noção de determinação social à de determinantes sociais da saúde. Saúde em Debate, 41(112), 63-76.

Guzzo, R., \& Lacerda Júnior, F. (2007). Fortalecimento em tempo de sofrimento: reflexões sobre o trabalho do psicólogo e a realidade brasileira. Interamerican Journal of Psychology, 41(2), 231-240.

International Monetary Fund. (2019). World economic outlook: Growth slowdown, precarious recovery. Washington: International Monetary Fund.

Lacerda Júnior, F. (2010). Psicologia para fazer a crítica? Apologética, individualismo e marxismo em alguns projetos psi. (Tese, Programa de Pós-Graduação em Psicologia, Pontifícia Universidade Católica de Campinas).

Lacerda Júnior, F. (2013). Capitalismo dependente e a psicologia no Brasil: Das alternativas à psicologia crítica. Teoría y crítica de la psicología, 3, 216-263. 
Magno, L., \& Paim, J. (2015). Dos clamores das ruas aos rumores no Congresso: Uma análise da conjuntura recente da saúde no Brasil. RECIIS, 9(4), 1-14.

Martín-Baró, I. (1996). O papel do Psicólogo. Estudos de Psicologia (Natal), 2(1), 7-27.

Martín-Baró, I. (2006). Hacia una Psicología de la Liberación. Revista Electrónica de Intervención Psicosocial y Psicología Comunitaria, 1(2), 7-14.

Martín-Baró, I. (2015). El papel del psicólogo en un proceso revolucionario. Teoría y Crítica de la Psicología, 6, 487-490.

Marx, K. (2008). Contribuição à crítica da economia política. São Paulo: Expressão Popular. [Original Publicado em 1859].

Marx, K. (2010). Crítica da filosofia do direito de Hegel. São Paulo: Boitempo Editorial. [Original Publicado em 1844].

Mendes, A., Ianni, A. M. Z., Marques, M. C. C., Ferreira, M. J., \& Silva, T. H. S. (2017). A contribuição do pensamento da saúde coletiva à economia política da saúde. Saúde e Sociedade, 26(4), 841-860.

Meszáros, I. (2011). A crise estrutural do capital. São Paulo: Boitempo.

Morais, A., \& Lacerda Júnior, F. (2019). Ideologia, individualismo e psicologia: O modo de produção capitalista e a experiência subjetiva. Teoría y Crítica de la Psicología, 12, 163-184.

Netto, J. P. (2001). Cinco notas a propósito da "Questão Social". Temporalis - Revista da ABEPSS, 2(3), 41-49.

Netto, J. P. (2011). Introdução ao estudo do método de Marx. São Paulo: Expressão Popular.

Oxfam. (2018). Recompensem o trabalho, não a riqueza. Oxford: Oxfam. Recuperado de https://www.oxfam.org.br/recompensem-o-trabalho-nao-a-riqueza

Paim, J. S., \& Almeida Filho, N. (1998). Saúde coletiva: Uma "nova saúde pública" ou campo aberto a novos paradigmas? Revista de Saúde Pública, 32(4), 299-316.

Radis. (2003). Entrevista: Sérgio Arouca. Trabalho, Educação e Saúde, 1(2), 355-361.

Soares, A., \& Santos, N. R. (2014). Financiamento do Sistema Único de Saúde nos governos FHC, Lula e Dilma. Saúde em Debate, 38(100), 18-25.

Souza, D. O., Silva, S. E. V., \& Silva, N. O. (2013). Determinantes Sociais da Saúde: Reflexões a partir das raízes da "questão social". Saúde e Sociedade, 22(1), 44-56.

Vasconcelos, E. (2012). Cenário econômico, social e psicossocial no Brasil recente, e a crescente difusão do crack: Balanço e perspectivas de ação. O Social em Questão, 28, 149-186.

Viana, A. L. D., \& Silva, H. P. (2018). Meritocracia neoliberal e capitalismo financeiro: Implicações para a proteção social e a saúde. Ciência \& Saúde Coletiva, 23(7), 2107-2117. Yamamoto, O. H. (1987). A crise e as alternativas da psicologia. São Paulo: Edicon.

Yamamoto, O. H., \& Oliveira, I. F. (2010). Política Social e Psicologia: Uma trajetória de 25 anos. Psicologia: Teoria e Pesquisa, 26(n. esp.), 9-24.

Recebido em: 24/07/2019

última revisão: 23/11/2019

Aceito em: 02/12/2019 


\section{Sobre os autores:}

Pedro Henrique Antunes da Costa: Doutor em Psicologia pela Universidade de Juiz de Fora (UFJF). Professor da Graduação em Psicologia na Universidade de Brasília (UnB), Departamento de Psicologia Clínica. E-mail: phantunes.costa@gmail.com, Orcid: https://orcid.org/0000-0003-2404-8888

Kíssila Teixeira Mendes: Doutoranda e mestre em Psicologia pela Universidade Federal de Juiz de Fora (UFJF), Programa de Pós-Graduação em Psicologia. Bolsista CAPES. E-mail: kissilamm@hotmail.com, Orcid: https://orcid.org/0000-0002-7817-599X 
